Session 1626

\title{
True Triaxial Testing System for Geotechnical Engineering Education
}

\author{
Dayakar Penumadu \\ Department of Civil and Environmental Engineering \\ Clarkson University, Potsdam, NY 13699-5710
}

\begin{abstract}
The influence of stress path and drainage conditions on the strength of soils can be effectively conveyed to the undergraduate students in a laboratory environment. The objective of the present project is to demonstrate the above concepts using an automated electro-pneumatic controlled true triaxial testing device with flexible boundaries. The paper indicates the salient features of the components of that testing system to date. Two types of laboratory experiments are developed using the above device. The first experiment familiarizes the undergraduate with concepts related to static transducer calibration, analog to digital conversion, signal conditioning, software and hardware gain, and the problems of aliasing. The second experiment deals with the isotropic and anisotropic consolidation and testing of soil samples using predefined stress path. Stress and strain controlled static shear tests can be performed using the above device and essentially any stress path can be simulated through the data acquisition and control software. The primary objective of the laboratory exercises is to show the relevance of the various laboratory strength tests with actual field conditions using the same testing device and in the process explain the concepts related to electronic data acquisition and control. The significant advantage is that the same device can be used to illustrate the drained and undrained stress-strain characteristics of both isotropic and $\mathrm{K}_{\mathrm{o}}$ consolidated soil samples. The samples can be sheared under a predefined stress path and the observed pore pressure behavior (for undrained testing) can be compared. In line with the ongoing research trends, the plan is to device soil testing programs that examine the issues related to type of consolidation, stress path and the rate of loading. The information related to the design and fabrication of a flexible boundary true triaxial testing (TTT) device for use in Civil and Environmental Engineering undergraduate education is presented in this paper. The author from his own experience firmly believes that the concept of stress path effects and aspects related to the use of computers in acquiring and controlling the physical data can be effectively taught to the undergraduate students in a laboratory testing course. These concepts can then be implemented in a foundation design course and is the incentive for developing the automated TTT setup. The portfolios and the role of two undergraduate students who were involved in the fabrication of this device is also presented. These two students were supported through an NSF-REU grant. The TTT device will be used for instructional purposes at Clarkson University, Potsdam, NY in Fall, 1996. The test setup will be used initially for performing two experiments: 1 )Transducer Calibration Experiment, 2) Soil Stress Path Testing. The details of the proposed experiments are included in the paper.
\end{abstract}




\section{Introduction and the Need for True Triaxial Testing of Soil}

The importance of stress path and drainage conditions on strength and deformation characteristics of soil has been well researched in the last three decades. Several technical papers exist which relate the normalized strength ratio with the type of laboratory and/or insitu test especially for undrained conditions. The relevance of various laboratory strength tests with actual field conditions for different types of loading are shown by Kulhawy and Mayne ${ }^{1}$. It is very important for the undergraduate student in the Civil and Environmental Engineering (CEE) to realize that the type of laboratory strength test has an important influence on the test results and thus has major role in the final design of the foundation. In the past at universities which have appropriate equipment, this aspect of demonstrating the role of stress path on the stress-strain curves has been demonstrated to undergraduates successfully by using triaxial test (using a cylindrical soil sample) and direct shear test (using a cylindrical or cubic shape soil sample). However the later testing facility is unavailable for students at Clarkson. One limitation with this approach is that it is difficult for the undergraduate to comprehend aspects related to anisotropic consolidation and shear testing.

The current trend of many manufacturers of geotechnical testing equipment (e.g. GEO-TEST, US LONG YEAR, WYKEHAM-FARRANCE, GEO-COMP) which are widely used by the consulting firms, is to use DOS based personal computer for automatic data acquisition and/or control and involve the use of transducers for measuring load, pressure and displacement. The author believes that the concept of stress path effects and aspects related to the use of computers in acquiring and controlling the physical data can be effectively taught to the undergraduate students in a laboratory testing course (CE 403). These concepts can then be implemented in a foundation design course (CE 415) and is the incentive for designing and developing the automated true triaxial testing system. This testing system will thus give the undergraduate, a comprehensive understanding of the factors influencing the strength of soils and the importance of the techniques that are used in performing such experiments and data collection.

\section{Relevance of the TTT Project to Clarkson CEE Program}

Civil Engineering Laboratory (CE403) and Geotechnical Engineering 11: Foundations (CE415) are the courses of interest in this project. CE403 is a required course for a B.S. Degree in Civil and Environmental Engineering at Clarkson University and is usually taken in the senior year. It is the goal of CE403 to apply the students' education from previous classes in Geotechnical Engineering (Soil Mechanics I and II), Structures and Mechanics (Statics, Strength of Materials, Structural Analysis, Steel Design, and Concrete Design), Hydraulics (Fluid Mechanics, Hydraulic Engineering), and Environmental Engineering (Water and Wastewater Treatment Processes, Water Quality Engineering, Hazardous Waste Management) to a series of labs. Classroom lectures and associated laboratory projects comprise the basis of this laboratory course. These labs are 'hands on' opportunities where students conduct experiments to demonstrate an engineering principle or to determine material characteristics. The objective of each experiment and the associated measurements that are required for the successful conduct of the experiment are described in a laboratory manual.

CE415 is an elective which is offered once a year. The course deals with the sub-surface investigation and geotechnical design of shallow and deep foundations for various types of soil. It also deals with the design of retaining walls and slope stability. The importance of choosing correct design strength parameters, be it undrained or drained situation, for varying stress path is emphasized in this course. This aspect of understanding 
the influence of stress path effects on the strength of soil is very difficult for undergraduate students without being involved in performing such experiments. Due to the low quality and small quantity of equipment presently available for undergraduate use, the variety and number of geotechnical labs that can be performed presently is limited. Presently there are 2 geotechnical labs: 1) Soil Classification that includes the evaluation of grain-size distribution curve using Sieve and Hydrometer Analysis, Evaluation of Atterberg Limits; 2) MoistureCompaction Relationships using Standard and Modified Proctor tests. The students currently do not have an opportunity to perform stress-strain testing for soils even for isotropic triaxial stress path. Students graduate without having hands-on experience with state-of-the-art equipment. In addition, it is difficult for the undergraduate to understand and correctly use the test data obtained from modern consulting geotechnical lab equipment that often involve the concept of stress path testing and some form of data acquisition and control.

\section{Undergraduate Assistance in the Design and Fabrication}

Two civil engineering undergraduate students, Mr. Chris Pletcher and Mr. David Malburg, were involved in the design and fabrication of consolidometer, cuboidal space frame and electronic control system. Both the students were supported through an NSF-REU supplemental grant to the NSF-ILI grant. Mr. Malburg was very familiar with working in machine shop and was instrumental behind the fabrication of the space frame and accessories. Mr. Pletcher had proficiency in software programming and was involved with the instrumentation, setup of the data acquisition system and writing VIEWDAC programs for closed loop control. Both students learning strengths and weaknesses were evaluated using the Kolb's learning cycle (Kolb, 1984) using the Learning Style Inventory (LSI) data. Based on this data, Chris was classified as an ACCOMMODATOR (AC-CE $=-7 \& \mathrm{AE}-\mathrm{RO}=10$ ) whose strengths are accomplishment, goal-orientation, decision implementation, adaptability and intuitive, trial and error learning. David was classified as a DIVERGER (AC-CE $=-4 \&$ AE$\mathrm{RO}=-2$ ) whose strengths are creativity, generation of alternatives, and recognition of problems and providing creative solutions. Thus, these two students fit the project requirements very well. It was also important for the author to get feedback from these undergraduates at various stages of development of TTT, for designing laboratory exercises that are at a level to be understood by the Clarkson undergraduate body.

\section{Design and Development of TTT}

The objective of the project was to develop an automatic true triaxial testing device that can be effectively used to simulate the desired stress path (e.g. triaxial compression, triaxial extension, simple shear, plane strain compression, plane strain extension, pressuremeter stress path) on a cubical soil sample using the same test setup. The test setup is fully automated with computer control for data acquisition. The test set up has an electropneumatic closed loop system and can perform both stress and strain control testing. A detailed design and development of the hardware and software of the automated TTT system including initial results on specific stress paths are described elsewhere (Penumadu, 1996) 8 . However, the major components that went into the system are briefly summarized in the following sections.

\section{Slurry Consolidometer}

Powdered soil-water mix is consolidated under $\mathbf{K}_{\mathrm{o}}$ conditions in a slurry consolidometer made of plexiglass to obtain a uniform 4 inch $(102 \mathrm{~mm})$ cubical specimen. The consolidometer consists of two chambers, a piston and a base. The heights of upper and lower chambers are 9 in. $(229 \mathrm{~mm})$ and 4 in. (102 $\mathrm{mm})$ 
respectively. The isometric view of it is shown in Figure 1. The wall of the lower chamber was reinforced to minimize lateral deformation during sample preparation. The interior surface of the lower chamber was lined with Teflon in order to minimize the wall friction at consolidation and extrusion stages. For the lab demonstrations, slurry made of kaolin (naturally occurring clay) with initial water content of twice its liquid limit will be used. This process gives repeatable and uniform specimens which can then be used by the undergraduates for various stress path testing and will be able to compare each group's results. This sample preparation technique will also be useful for understanding the concepts related to one dimensional consolidation of clays.

\section{True Triaxial Test Device}

For realistic simulation of the field conditions and for predictions based on plasticity models, it is desirable to test soil specimens under truly triaxial state of stress. The cuboidal space frame and the interfacing setup is such an apparatus which can apply three orthogonal stresses independently under the desired stress path. The boundary stresses are applied to the cuboidal-shaped specimen (obtained from the slurry consolidometer) through flexible membranes on each of the three pairs of faces of the specimen. The flexible membranes are effective for stress controlled tests where uniform stress distribution is possible. However, the uniformity of large strains is difficult to maintain. Plane strain or any other strain controlled test can be performed with flexible boundary loadings through step wise corrections using a trial and error approach through the computer control software. A detailed description of similar device was given by Sivakugan, 19872 and several major modifications were made in the hardware interface and pneumatic control by the author based on his experience with similar devices in calibration chamber testing (Penumadu, 1993) ${ }^{6}$. The space frame and pressure casings (assembly having pressure transducer's and LVDT's) attached to it is shown in Figure 2. A 4 in. (102 mm) soil sample "floats" in the $4.5 \mathrm{in}$. $(114 \mathrm{~mm})$ cubical cavity of the space frame and is confined with six identical rubber membranes. The specimen is loaded by the compressed air coming from the output port of Electric-Pneumatic transducers (Fairchild T6000). The computer will control the stress path by sending appropriate voltage inputs to the three E-P transducers through an analog output multiplexer (AOM 4). The cylindrical casing which contains the linear variable differential transformers (LVDT's) and the pressure transducers also serves as a holder of flexible membrane. The casings on opposite sides are connected by pressure tubing and thus equal pressures can be applied on the opposite sides of the specimen. All three directional pressures are controlled automatically through Electric-Pneumatic transducers. Pore Pressure at the center of the specimen is measured by a custom made needle piezometer. All the transducer inputs are interfaced to the computer through Keithley 500A with a 14 bit A/D converter, Analog Input Multiplexer (AMM2) and the Series 500A main frame. The input to the E-P transducers is through the Analog Output Multiplexer (AOM4). The entire system is closed loop using PID control available through VIEWDAC software, thus facilitating variable stress and strain path testing. Using the above test setup the following specific laboratory projects will be assigned for the undergraduates registered in the course CE 403 for the Fall' 96.

\section{Laboratory Exercises}

Transducer Calibration Experiment: The objective is to familiarize the undergraduate student with the concepts behind static transducer calibration and measurement. The students will calibrate a pressure transducer and an A.C type L.V.D.T by applying the known amounts of pressure or deformation and reading the voltage output from the data acquisition software (VIEWDAC). They will then plot the measurand versus output voltage and obtain the calibration factors. The importance of supply voltage and non-linear portion of L.V. D.T 


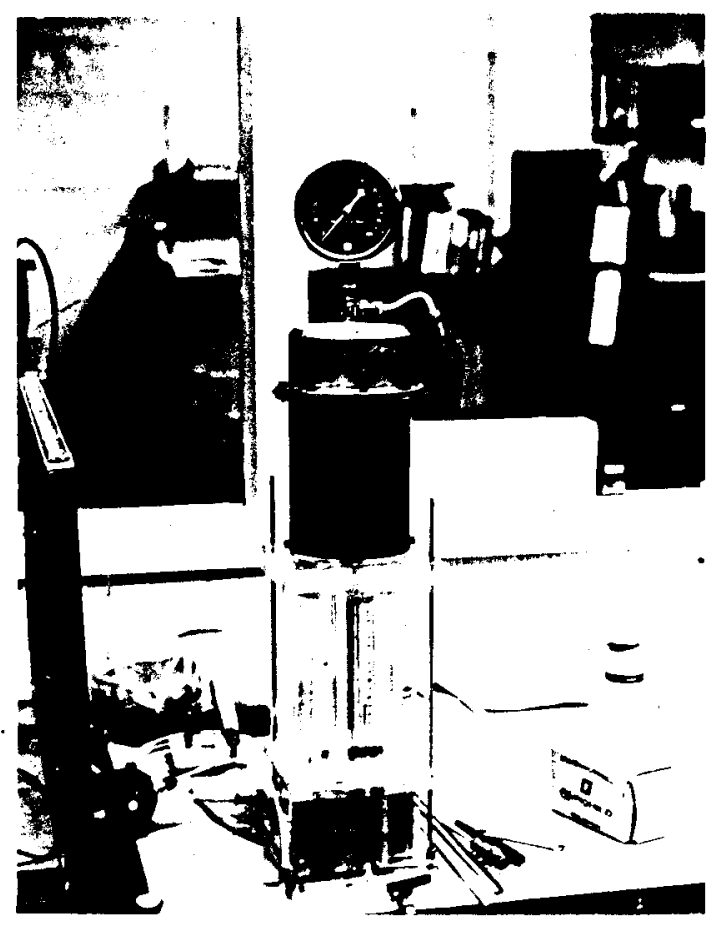

Figure 1: $\mathbf{K}_{\mathbf{o}}$ Slurry Consolidometer

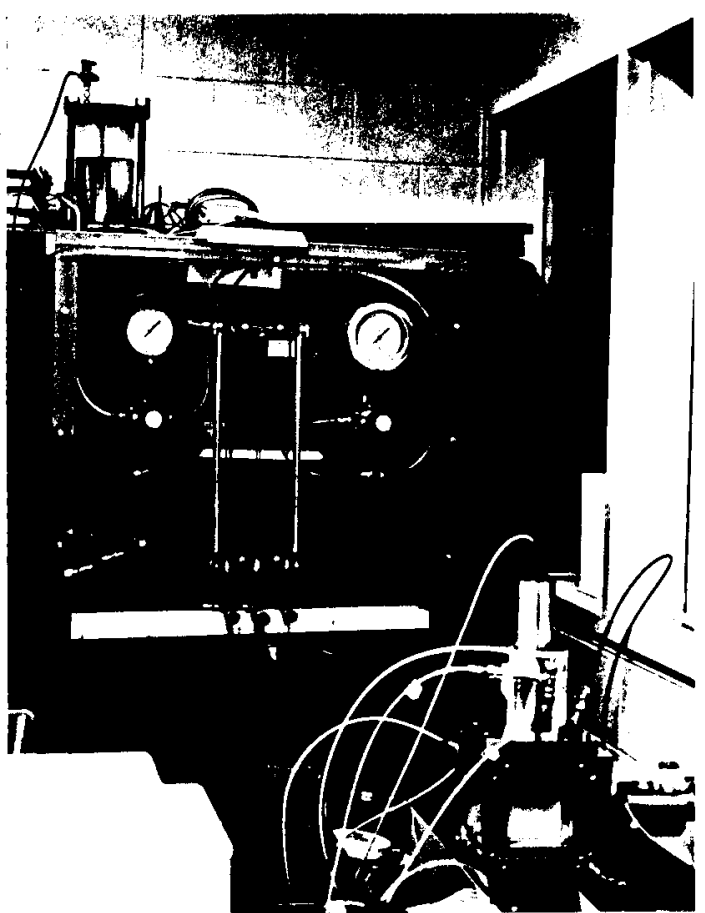

Figure 2: Partially Assembled Space Frame

calibration curve will be emphasized. The theory behind analog to digital conversion and problems of aliasing will also be explained. The importance of signal conditioning, hardware and software gain and single versus differential ended inputs will be explained.

Soil Stress Path Testing: The class will be divided into five or six groups. A batch of kaolin with appropriate water content will be mixed using a heavy duty mixer and the block samples for individual groups will be prepared. The groups will now be asked to consolidate the samples using true triaxial test device for known pre-consolidation pressures. The consolidation time of the specific kaolin used (AKROCHEM) is relatively quick and is thus feasible. At the end of the consolidation under $\mathbf{K}_{\mathbf{o}}$ or isotropic state, a specific stress path (pre-programmed in the computer) will be used to obtain stress-strain and pore-pressure-strain curves for undrained situation. The test results of all the groups (for different and similar stress paths) will now be used to demonstrate the importance of type of consolidation, stress path and rate of loading.

\section{Summary and Conclusions}

This paper presented the salient features of an automated electro-pneumatic control flexible wall true triaxial testing system being developed that will be used for geotechnical engineering education at Clarkson university during Fall, 1996. Two types of laboratory experiments are developed using this device. The first experiment familiarizes the undergraduate with concepts related to static transducer calibration, analog to digital conversion, signal conditioning, software and hardware gain, and the problems of aliasing, The second 
experiment deals with the isotropic and anisotropic consolidation and testing of soil samples using predefine stress path. Stress and strain controlled static shear tests can be performed using the above device and essentially any stress path can be simulated through the data acquisition and control software. The portfolios and the role of two undergraduate students who were involved in the design and fabrication of this device is also presented. The primary objective of the laboratory exercises is to show the relevance of the various laboratory strength tests with actual field conditions using the same testing device and in the process explain the concepts related to electronic data acquisition and control. The significant advantage is that the same device can be used to illustrate the drained and undrained stress-strain characteristics of both isotropic and $\mathbf{K}_{\mathbf{0}}$ consolidated soil samples.

\section{Acknowledgments}

The author wishes to acknowledge the support of National Science Foundation through ILI grant DUE9452059 and its supplemental REU grant.

\section{References}

[1] Kulhawy, F.H. and Mayne, P. W., "Manual On Estimating Soil Properties For Foundation Design", Report EL-6800, Electric Power Research Institute, Palo Alto, 1990.

[2] Sivakugan, N., "Anisotropy and Stress Path Effects in Clays", Ph.D.Thesis, Purdue University, West Lafayette, IN, 1987.

[3] Skandarajah A., "Strain Rate and Stress Relaxation in Simulated Pressuremeter Testing in Clays, Ph.D. Thesis, Purdue University, W. Lafayette, IN, 1992.

[4] Penumadu, D., Skandarajah, A., and Chameau, J.-L., "Model Pressuremeter Testing in an Automated Flexible Wall Chamber", First International Symposium on Calibration Chamber Testing, Potsdam, NY, 1991.

[5] Skandarajah, A., Penumadu, D., and Chameau, J.-L., "Strain Rate Effects in Pressuremeter Testing", $A S C E$ Engineering Mechanics Conference, Columbus, OH, 1991.

[6] Penumadu, D., "Strain Rate Effects in Pressuremeter Testing and Neural Network Approach for Soil Modeling”, Ph.DThesis, Georgia Institute of Technology, Atlanta, GA, 1993.

[7] Kolb, D. A., "Experiential Learning: Experience as the Source of Learning and Development", Prentice-Hall, Englewood Cliffs, N.J., 1984.

\section{Biographical Information}

DAYAKAR PENUMADU: Dr. Penumadu has been an assistant professor in the department of Civil and Environmental Engineering at Clarkson University since 1993. His graduate degrees are: Ph. D., in Geotechnical Engineering from Georgia Institute of Technology, Atlanta, GA (1993); M. S., in Civil Engineering from Purdue University, W. Lafayette, IN (1991); M. S., in Civil Engineering from University of Kentucky, Lexington, KY(1989). He was recently awarded Tau Beta Pi faculty award for Clarkson University outstanding teacher for 1995. 